\title{
In Vitro Shoot Bud Differentiation from Hypocotyl Explants of Chili Peppers (Capsicum annuum L.)
}

\author{
Owk ANIEL KUMAR, Sape SUBBA TATA \\ Andhra University,_Department of Botany,Visakhapatnam,India; owkanielkumar@yahoo.com;s_tata_s@yahoo.co.in (correspondingauthor)
}

\begin{abstract}
Chili pepper (Capsicum annuum L.) is an economically important spice crop in tropical and subtropical countries. In vitro plant regeneration was obtained from $15^{\text {th }}$ day old hypocotyl explants of three chili pepper cultivars (Capsicum annuum L., var. 'X-235', var. 'PC-1' and var. 'Pusa Jwala'). Among the genotypes of Capsicum L. var. 'X-235' responded better than the var. 'PC-1' and var. 'Pusa Jwala'. MS medium containing BAP $(4.0 \mathrm{mg} / \mathrm{l})$ and IAA $(0.5 \mathrm{mg} / \mathrm{l})$ was found to be the best medium for the production of maximum number of shoot buds in all the genotypes of chili pepper i.e., $6.80 \pm 0.16$ (var. 'X-235'), $5.00 \pm 0.19$ (var. 'PC-1') and $4.80 \pm 0.12$ (var. 'Pusa Jwala'). The shoots were rooted on MS medium fortified with IBA $(0.5 \mathrm{mg} / \mathrm{l})$. Rooted plants were hardened and transplanted to the soil. The plants showed $80-90 \%$ survival during transplantation.
\end{abstract}

Keywords: BAP, hypocotyl, IAA, IBA, MS medium, rooting

\section{Introduction}

Capsicum annuum L. is an economically important crop plant belonging to the family Solanaceae; two main consumption types of pepper- spice and vegetable are prevalent throughout the world. A major constraint facing the chili crop is the high incidence of pests and diseases (Morrison et al., 1986). In order to facilitate the development of plant biotechnology based cultivar improvement for this crop, considerable effort has been devoted in developing and optimizing efficient in vitro regeneration protocols. Even though other Solanaceae members easily undergo morphogenesis, chili was found to be highly recalcitrant (Ochoa-Alejo and Ramirez-Malagon, 2001; Steinitz et al., 1999). The regeneration capacity of chili plants has been carried out successfully from hypocotyl explants (Borychowski et al., 2002; Christopher and Rajam, 1994, 1996; Fari and Czako, 1981; Gunay and Rao, 1978; Mok and Norzulaani, 2007; Rodeva et al., 2006; Sanatombi and Sharma, 2008; Singh and Shukla, 2001). However, many of these reports suggest a strong influence of the genotype on the regeneration process (Christopher and Rajam, 1996; Ochoa-Alejo and Ireta-Moreno, 1990; Ramirez-Malagon and Ochoa-Alejo, 1996; Szasz et al., 1995). The present investigation, describes the culture of hypocotyl explants of three cultivars of $C$. annuum $\mathrm{L}$. The study was undertaken to determine the regeneration potential and to develop efficient in vitro plant regeneration protocol for the three genotypes of $C$. annuum $\mathrm{L}$.

\section{Materials and methods}

Seeds of three genotypes of $C$. annuum L. viz., var. 'X-235', var. 'PC-1' and var. 'Pusa Jwala' were obtained from Sutton and Seeds, Calcutta, India. The seeds were surface sterilized with $0.1 \% \mathrm{HgCl}_{2}$, repeatedly washed in sterile distilled water and inoculated on MS (Murashige and Skoog, 1962) basal medium for germination. The hypocotyl explants were about 2-3 $(\mathrm{cm})$ in length, derived from 15 days old in vitro germinated seedlings cultured on MS medium supplemented with various concentrations of auxins like IAA (indole-3-acetic acid) and IBA (indole-3butyric acid) and cytokinin BAP (6- benzyl aminopurine). The $\mathrm{pH}$ of the media was adjusted to 5.8 and solidified with agar, before autoclaving. For shoot bud induction the explants were placed on MS medium supplemented with BAP (1.0-5.0 mg/l) alone or combination with IAA (0.5 $\mathrm{mg} / \mathrm{l})$ and subculture at two weeks to the same medium. The number of shoot buds were recorded after eight weeks of culture. To test their rooting, capacity the elongated shoots, were excised and transferred to different concentrations of IAA (0.25-1.0 mg/l) and IBA (0.25-1.0 mg/l). The rooting i.e., number of roots and length of the root per shoot were noted after four weeks of culture. Plants with roots were transferred during four weeks, after washing of the agar with distilled water, to pot with a mixture of soilrite $(1: 1)$. Potted plantlets were covered with transparent polythene membrane to ensure high humidity and watered every third day with half strength MS salt solution for two weeks in order to acclimatize plants to field conditions. After four weeks, acclimatized plants were transferred to pots containing normal garden soil and maintained in greenhouse under natural day length conditions. All the cultures were maintained in a growth chamber at a temperature of $25 \pm 2^{\circ} \mathrm{C}$ and 16 hours photoperiod provided by white fluorescent tubes $\left(30 \mu \mathrm{mol} \mathrm{m}^{-2} \mathrm{~S}^{-1}\right)$. All the experiments were repeated thrice; each treatment for shoot bud 
Tab. 1. Effect of BAP and IAA on shoot bud induction from hypocotyl explants of three genotypes of $C$. annuum $\mathrm{L}$.

\begin{tabular}{|c|c|c|c|c|c|}
\hline \multirow[t]{2}{*}{ No. } & \multicolumn{2}{|c|}{$\begin{array}{c}\text { Growth } \\
\text { regulators } \\
\text { mg/l) }\end{array}$} & \multicolumn{3}{|c|}{ Genotype } \\
\hline & BAP & IAA & $\begin{array}{l}\text { C. annuum } \\
\text { var. 'X-235' }\end{array}$ & $\begin{array}{l}\text { C. annuum } \\
\text { var. 'PC-1' }\end{array}$ & $\begin{array}{l}\text { C. annuum var. } \\
\text { 'Pusa Jwala' }\end{array}$ \\
\hline 1 & - & - & - & - & - \\
\hline 2 & 1.0 & - & $0.83 \pm 0.02$ & $0.52 \pm 0.04$ & $0.40 \pm 0.09$ \\
\hline 3 & 2.0 & - & $1.00 \pm 0.05$ & $0.64 \pm 0.02$ & $0.57 \pm 0.03$ \\
\hline 4 & 3.0 & - & $1.06 \pm 0.02$ & $1.00 \pm 0.07$ & $0.94 \pm 0.01$ \\
\hline 5 & 4.0 & - & $1.10 \pm 0.06$ & $1.08 \pm 0.02$ & $1.00 \pm 0.08$ \\
\hline 6 & 5.0 & - & $1.00 \pm 0.03$ & $0.90 \pm 0.07$ & $0.85 \pm 0.05$ \\
\hline 7 & 1.0 & 0.5 & $2.20 \pm 0.04$ & $2.00 \pm 0.08$ & $1.83 \pm 0.18$ \\
\hline 8 & 2.0 & 0.5 & $3.10 \pm 0.20$ & $2.90 \pm 0.25$ & $1.97 \pm 0.27$ \\
\hline 9 & 3.0 & 0.5 & $4.90 \pm 0.12$ & $3.82 \pm 0.20$ & $3.62 \pm 0.19$ \\
\hline 10 & 4.0 & 0.5 & $6.80 \pm 0.16$ & $5.00 \pm 0.19$ & $4.80 \pm 0.12$ \\
\hline 11 & 5.0 & 0.5 & $5.20 \pm 0.25$ & $4.80 \pm 0.30$ & $4.50 \pm 0.20$ \\
\hline
\end{tabular}

induction from hypocotyl explants and rooting of shoot buds consisted of twenty and ten replicates respectively.

\section{Results and discussions}

The data from (Tab. 1) show that the cultivated hypocotyl explants from the three studied $C$. annuum $\mathrm{L}$. genotypes develop shoot buds with reference to the media composition. In this study, we obtained successful regeneration with $15^{\text {th }}$ day old explants of the three genotypes. The results obtained were agreed according to data reported by Borychowski et al. (2002) and Mok and Norzulaani (2007). The genotypes showed considerable variation in multiple shoot bud number ranged from 0.4 to 6.8 shoot buds per explant. The results are in conformity with the findings of Gunay and Rao (1978); Christopher and Rajam (1996); Ramirez-Malagon and Ochoa-Alejo (1996); Sanatombi and Sharma (2008) that reveals the regeneration of plants from hypocotyl explants in diverse cultivars of Capsicum L. The maximum number of shoot buds per explant was registered on an MS medium supplemented with BAP $(4.0 \mathrm{mg} / \mathrm{l})$ and IAA $(0.5 \mathrm{mg} / \mathrm{l})$ (Fig. 1 a) for all three genotypes i.e., $6.80 \pm 0.16$ (var. 'X-235'), $5.00 \pm 0.19$ (var. 'PC-1') and $4.80 \pm 0.12$ (var. 'Pusa Jwala') while, the lowest number of shoots per explant were recorded in MS medium fortified with BAP $(1.0 \mathrm{mg} / \mathrm{l})$ i.e., $0.83 \pm 0.02$ (var. 'X-235'), $0.52 \pm 0.04$ (var. 'PC-1') and $0.40 \pm 0.09$ (var. 'Pusa Jwala') (Tab. 1). The results of the above indicate that the plant hormonal combination of 4 $\mathrm{mg} / \mathrm{l}$ (BAP) and $0.5 \mathrm{mg} / \mathrm{l}$ (IAA) was better than any other combination. The results are in agreement with earlier reports of Gunay and Rao (1978); Christopher and Rajam (1994, 1996); Ramage and Leung (1996); Sanatombi and Sharma (2008). This may be due to auxins or cytokinins used alone or in combination, which is supposed to be the result of the promotion of biosynthesis or inhibition of degradative metabolism, theory shared also by Singh and Shukla (2001). The shoots derived from hypocotyl explants were excised and implanted on MS medium supplemented with IAA and IBA in three different concentrations (Tab. 2). The better response of rooting was higher in the MS medium supplemented with IBA $(0.5 \mathrm{mg} / \mathrm{l})$. The best rooting (i.e., number of roots $(11.0 \pm 0.25)$ and length of root $(5.20 \pm 0.32)$ per shoot bud were achieved in the genotype 'X-235' (Fig. 1 b). Similar results were obtained by Sanatombi and Sharma (2006) on cultivars of $C$. annuum L. Our results show that 4.8 to 6.8 shoots per hypocotyl, which can be considered as a very good regeneration in comparison to 2-5 shoots reported by Gunay and Rao (1978); Christopher and Rajam (1996); Sanatombi and Sharma (2008). The regenerated plants showed $80-90 \%$ survival during hardening and acclimatization (Fig. $1 \mathrm{c}$ and d) and there are no observable differences between the parent plant and in vitro raised plants. The transplanted plantlets established well in pots and in the field.

Tab. 2. Effect of Auxins on rooting of in vitro induced shoot buds from hypocotyl explants of three genotypes of C. annuum L.

\begin{tabular}{|c|c|c|c|c|c|c|c|c|}
\hline \multirow[t]{3}{*}{ S. No. } & \multicolumn{2}{|c|}{ Auxins (mg/l) } & \multicolumn{6}{|c|}{ Genotype } \\
\hline & \multirow[t]{2}{*}{ IAA } & \multirow[t]{2}{*}{ IBA } & \multicolumn{2}{|c|}{ C. annuum var. 'X-235' } & \multicolumn{2}{|c|}{ C. annuum var. 'PC-1' } & \multicolumn{2}{|c|}{ C. annuum var. 'Pusa Jwala' } \\
\hline & & & $\begin{array}{c}\text { No. of Roots/ } \\
\text { Shoot }\end{array}$ & $\begin{array}{c}\text { Root length } \\
(\mathrm{cm})\end{array}$ & $\begin{array}{c}\text { No. of Roots/ } \\
\text { Shoot }\end{array}$ & $\begin{array}{c}\text { Root length } \\
(\mathrm{cm})\end{array}$ & $\begin{array}{c}\text { No. of Roots/ } \\
\text { Shoot }\end{array}$ & $\begin{array}{c}\text { Root length } \\
(\mathrm{cm})\end{array}$ \\
\hline 1 & - & - & - & - & - & - & - & - \\
\hline 2 & 0.25 & - & $7.00 \pm 0.28$ & $2.60 \pm 0.28$ & $5.00 \pm 0.20$ & $1.80 \pm 0.30$ & $5.00 \pm 0.18$ & $1.60 \pm 0.20$ \\
\hline 3 & 0.50 & - & $9.00 \pm 0.11$ & $3.20 \pm 0.20$ & $8.00 \pm 0.19$ & $2.70 \pm 0.16$ & $7.00 \pm 0.14$ & $2.80 \pm 0.11$ \\
\hline 4 & 1.00 & - & $6.50 \pm 0.34$ & $2.40 \pm 0.25$ & $6.00 \pm 0.28$ & $2.00 \pm 0.20$ & $4.80 \pm 0.24$ & $1.80 \pm 0.13$ \\
\hline 5 & - & 0.25 & $9.00 \pm 0.49$ & $4.60 \pm 0.20$ & $8.20 \pm 0.35$ & $4.10 \pm 0.25$ & $7.60 \pm 0.37$ & $3.80 \pm 0.27$ \\
\hline 6 & - & 0.50 & $11.00 \pm 0.25$ & $5.20 \pm 0.32$ & $9.00 \pm 0.20$ & $4.80 \pm 0.26$ & $9.00 \pm 0.15$ & $4.60 \pm 0.30$ \\
\hline 7 & - & 1.00 & $8.00 \pm 0.45$ & $3.40 \pm 0.26$ & $6.00 \pm 0.22$ & $3.00 \pm 0.19$ & $5.50 \pm 0.29$ & $4.00 \pm 0.19$ \\
\hline
\end{tabular}

${ }^{*}$ Results are mean of ten replicates $(10 \mathrm{X} 3) \pm \mathrm{SE}$ 
68

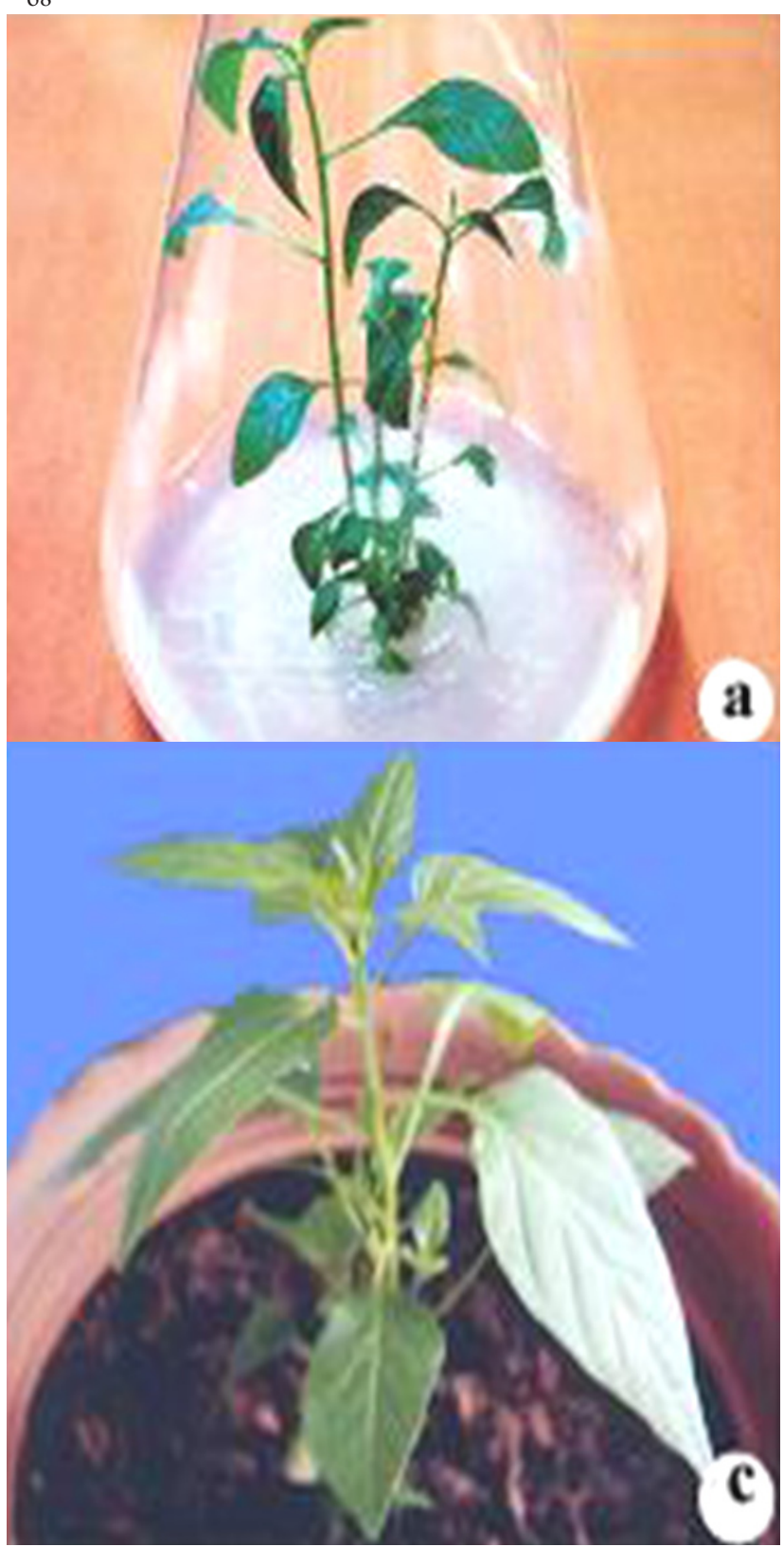

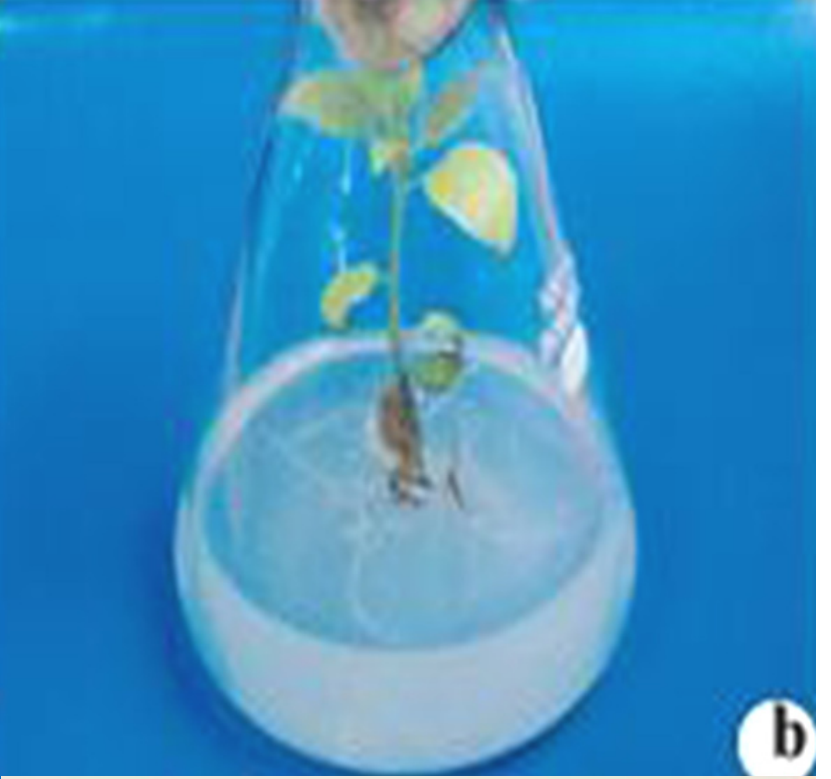

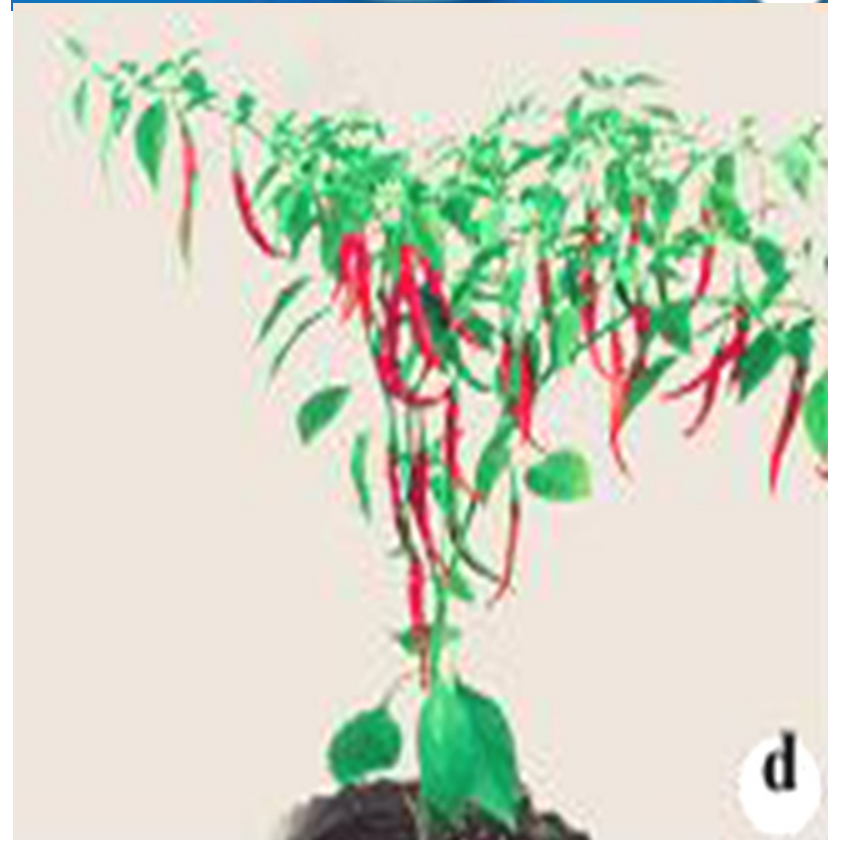

Fig. 1. In vitro shoot bud differentiation on Capsicum annuum L. var. 'X-235': (a) Induction of multiple shoot buds from hypocotyl explant; (b) Rooted plantlet; (c) Growth of transplanted plantlet in pot; (d) Fully developed plant with good fruit set

\section{Conclusions}

The present study reports that $15^{\text {th }}$ day old hypocotyl explants of three genotypes of $C$. annuum L. showed variation from multiple shoot bud number from one another, among the genotypes var. ' $\mathrm{X}-235$ ' responded better than the var. 'PC-1' and var. 'Pusa Jwala'. The study revealed that 4.8 to 6.8 shoot buds per explant were achieved in genotypes of $C$. annuum L. in MS medium supplemented with BAP $(4.0 \mathrm{mg} / \mathrm{l})$ and IAA $(0.5 \mathrm{mg} / \mathrm{l})$. The genotypes selected for the study and the methods used for in vitro regeneration and rooting, can be applied to increase the efficiency of transformation protocols using hypocotyls as explant source.

\section{Acknowledgements}

One of the authors (O. Aniel Kumar) is grateful to UGC-SAP, Department of Botany, Andhra University, Visakhapatnam.

\section{References}

Borychowski, A., K. Niemirowicz-Szczytt and M. Jedraszko (2002). Plant regeneration from sweet pepper (Capsicum annuum L.) hypocotyl explants. Acta Physiologiae 
Plantarum. 24(3):257-264.

Christopher, T. and M. V. Rajam (1994). In vitro clonal propagation of Capsicum spp. Plant Cell, Tissue and Organ Culture. 38:25-29.

Christopher, T. and M. V. Rajam (1996). Effect of genotype, explant and medium on in vitro regeneration of red pepper. Plant Cell, Tissue and Organ Culture. 46: 245-250

Fari, M. and M. Czako (1981). Relationship between position and morphogenetic response of pepper hypocotyls explants cultured in vitro. Scientia Horticulturae. 15: 207-213.

Gunay, A. L. and P. S. Rao (1978). In vitro plant regeneration from hypocotyls and cotyledon explants of red pepper (Capsicum). Plant Science Letters. 11:365-372.

Mok, S. H. and K. Norzulaani (2007). Trouble shooting for recalcitrant bud formation in Capsicum annuum var. Kulai. Asia Pacific Journal of Molecular Biology and Biotechnology. 15(1):33-38.

Morrison, R. A., R. E. Koning and D. A. Evans (1986). Pepper, p. 552-573. In: D.A. Evans, W. R. Sharp and P. V. Ammirato (Eds.). Handbook of Plant Cell Culture. Vol. 4 Macmillan, New York.

Murashige, T. and F. Skoog (1962). A revised medium for rapid growth and bioassays with tobacco tissue cultures. Physiology Plantarum. 15:473-497.

Ochoa-Alejo, N. and L. Ireta-Moreno (1990). Cultivar differences in shoot- forming capacity of hypocotyl tissues of chili peppers (Capsicum annuum L.) cultured in vitro. Scientia Hort. 42:21-28.

Ochoa-Alejo, N. and R. Ramirez-Malagon (2001). In vitro chili pepper biotechnology. In Vitro Cellular Developmental Biology-Plant. 37:701-729.
69

Ramage, C. M. and W. M. Leung (1996). Influence of BA and Sucrose on the competence and determination of pepper (Capsicum annuum L. var. Sweet Banana) hypocotyls cultures during shoot formation. Plant Cell Reports. 15: 974-979.

Ramirez-Malagon, R. and N. Ochoa-Alejo (1996). An improved and reliable chilli pepper (Capsicum annuum L.) plant regeneration method. Plant Cell Reports. 16:226-231.

Rodeva, V., S. Grozeva and V. Todorova (2006). In vitro answer of Bulgarian pepper (Capsicum annuum L.) varieties. Genetika. 38(2):129-136.

Sanatombi, K. and G. J. Sharma (2006). In vitro regeneration and mass multiplication of Capsicum annuum L. Journal of Food, Agriculture \& Environment. 4(1):205-208.

Sanatombi, K. and G. J. Sharma (2008). In vitro plant regeneration in six cultivars of Capsicum spp. using different explants. Biologia Plantarum. 52(1):141-145.

Singh, R. R. and R. Shukla (2001). In vitro shoot differentiation in Capsicum annuum (L.) var. Accuminatum. J. Indian. Bot. Soc. 80:301-303.

Steinitz, B., D. Wolf, T. Matzevitch-Josef and A. Zelcer (1999). Regeneration in vitro and genetic transformation of pepper (Capsicum spp.): The current state of art. Capsicum and Eggplant News Lett. 18:9-15.

Szasz, A., G. Nervo and M. Fari (1995). Screening for in vitro shoot forming capacity of seedling explants in bell pepper (Capsicum annuum L.) genotypes and efficient plant regeneration using thidiazuron. Plant Cell Reports. 14:666669. 